BMJ Open Ophthalmology

\title{
LncRNAs in genetic basis of glaucoma
}

Yacouba Cissé, Lang Bai, Ting Meng

To cite: Cissé $Y$, Bai L, Meng T. LncRNAs in genetic basis of glaucoma. BMJ Open Ophthalmology 2018;3:e000131. doi:10.1136/ bmjophth-2017-000131

Received 9 November 2017 Revised 19 January 2018 Accepted 2 March 2018

Check for updates

Department of Ophthalmology, Nanfang Hospital, Southern Medical University, Guangzhou, China

Correspondence to Dr Lang Bai; bailangsfy@126. com

\section{ABSTRACT}

Glaucoma is an umbrella term used to designate a heterogeneous group of ocular disorders characterised by progressive excavation of the optic disc, optic atrophy and gradual loss of the visual field caused by the slow death of retinal ganglion cells and their axons. Glaucoma can potentially lead to blindness if left untreated. It usually starts from the periphery and progresses gradually toward the centre of the visual field. Vision loss caused by glaucoma is irreversible and causes a heavy burden on affected families and society, therefore the importance of early diagnosis and prevention should be emphasised. Genetic factors appear to play a role in glaucoma pathogenesis; it has been shown that individuals with a positive family history are at a greater risk because they are more likely predisposed be affected. Notable advances have been recorded in the past decade concerning the genetic and environmental factors likely to contribute or cause glaucoma with the discovery of multiple glaucomaassociated genes and genetic loci. Thorough investigations by a handful of studies on the function of long non-coding RNAs discovered that, although lacking protein-coding potential, IncRNAs can still participate in the regulation of gene expression at various levels, thus their possible implication in different disease aetiologies. In this review, we focus on the IncRNAs characteristics and its regulation, and summarise these results from separate, independent, glaucoma-related studies in addition to discussing possible pathways by which IncRNAs might contribute to glaucoma.

\section{INTRODUCTION}

Glaucoma is an umbrella term used to designate a heterogeneous group of ocular disorders characterised by optic nerve damage that leads to vision loss and ultimately blindness if untreated and; usually starts from the periphery and progresses gradually towards the centre of the visual field. ${ }^{1}$

The number of people with glaucoma (primary open angle glaucoma (POAG) and primary angle closure glaucoma (PACG) combined) worldwide was estimated to be around 60.5 million in 2010. This number will increase significantly in the future, and it has been estimated that by 2020, approximately 79.6 million people will be affected, including 3 million in the USA. ${ }^{23}$ According to recent studies, the number of people affected by glaucoma worldwide will reach 111.8 million by 2040 , with Africa and Asia being most heavily affected. ${ }^{4}$ Chinese patients with PACG account for nearly half of PACG cases worldwide. ${ }^{3}$ According to the $\mathrm{WHO}$, it is currently the leading cause of irreversible blindness worldwide, despite the existence of an indisputable variation in its subtypes and risks among races and countries. ${ }^{5}$

Vision loss caused by glaucoma is irreversible and causes a heavy burden on affected families and society; therefore, the importance of early diagnosis through relevant examinations of suspicious cases to facilitate early detection and prevention; and avoid high intraocular pressure (IOP)-associated damage to the optic nerve should be emphasised.

Genetic factors seem to play an undeniable role in glaucoma pathogenesis; it has been shown that individuals with a positive family history are at a greater risk because they have a predisposition towards the condition. ${ }^{6}{ }^{7}$ Since the discovery of multiple glaucoma-associated genes and genetic loci in the past decade, notable advances have been recorded concerning the genetic and environmental factors likely to contribute to or cause glaucoma. $^{8-10}$

Recent recognition of the crucial functional importance of the non-coding region of the genome in normal development and physiology has focused increasing attention on its potential to contribute towards disease aetiology. IncRNAs are defined as non-protein-coding transcripts with a size ranging from 200 to $100000 \mathrm{nt}$; although lacking protein-coding potential, lncRNAs can still participate as RNA in the regulation of gene expression at various levels and are reportedly implicated in different disease aetiologies. ${ }^{11}$

Despite the fact that lncRNAs have been said to be implicated in normal neural development ${ }^{12}$ and progression of neurodegenerative diseases, including Alzheimer disease, ${ }^{13}$ and previously linked to multiple disease aetiologies, the proper connections and pathways they may use to influence the susceptibility to developing glaucoma, which is also characterised by nerve damage, have not yet been completely elucidated.

In this article, we review underlining mechanisms and risk factors for developing glaucoma, focus on the characteristics and regulation of lncRNAs and aim to 
demonstrate their implication in glaucoma pathogenesis by summarising results from separate, independent, glaucoma-related studies.

\section{GENETIC ASSOCIATIONS OF LNCRNA AND GLAUCOMA CDKN2B-AS1}

There are several genes in the 9p21 genomic region: CDKN2B-AS1, also known as ANRIL (antisense non-coding RNA in the INK4 locus); cyclin-dependent kinase inhibitor 2B (CDKN2B) and cyclin-dependent kinase inhibitor 2A (CDKN2A). ${ }^{14}$

Recent genome-wide association studies (GWAS) have remarkably shown the association of single nucleotide polymorphisms (SNPs) in this region with various human diseases, including notably, coronary artery disease, ${ }^{15}$ diabetes, ${ }^{16}$ ischaemic stroke, ${ }^{17}$ cranial and aortic aneurysm, ${ }^{18}$ glioma, ${ }^{19}$ malignant melanoma ${ }^{20}$ as well as many cancers. ${ }^{19}$

CDKN2B-AS1 is a long non-coding RNA in the antisense direction compared with CDKN2A and CDKN2B. ${ }^{21}$ Its exact biological function is largely unknown. The molecular mechanisms underlying the association between ANRIL and POAG are still not well understood. ${ }^{22}$ The occurrence of polymorphisms at these loci may alter the expression of the target genes responsible for regulating the cell cycle or act through epigenetic mechanisms, subsequently inducing a tendency towards retinal ganglion cell (RGC) apoptosis and glaucoma. ${ }^{23-25}$ Another study identified associations between 9p21 variants and glaucoma features, suggesting that the ANRIL region modifies the vulnerability of the optic nerve to cause glaucomatous change, further implying the role of ANRIL in modulating optic nerve degeneration. ${ }^{26}$

\section{Glaucoma-associated variants}

Numerous genetic variations have been associated with an increased risk of POAG in the past decade. The corresponding SNPs have been identified by different GWAS and are located in and around the CDKN2B-AS1. ${ }^{24} 2728$ Actually, each glaucoma-associated SNP does in fact possess two alleles: one associated with a decreased POAG risk (protective variants) and the other one associated with an increased POAG risk (risk variants). Variants such as rs7049105 and rs2151280 were not only associated with a reduced POAG risk, but have also been linked with a smaller cup-to-disc ratio (CDR) observed at disease presentation. Although primarily associated with a reduced risk in case-control studies, an association was also established between rs573687 and the age at diagnosis of patients with POAG, with people carrying this allele developing the disease at least 5 years later than non-carriers. ${ }^{26}$

The rs2157719 allele was described as not only having an association with an increased chance of peripheral visual field loss and smaller CDR, but is widely known to play a major role in the occurrence of both normal tension glaucoma (NTG) and exfoliation glaucoma. It has further been reported to be implicated in reduced
POAG risk in Asian, African and Caucasian populations in diverse studies. ${ }^{23}{ }^{29}$ rs32177992 was found to increase the risk of POAG, with carriers more prone to develop the disease and potentially harbouring a larger CDR at diagnosis. A larger optic disc has been shown to be more susceptible to IOP-related stress. Thus, this suggests an implication in the occurrence of glaucoma and the progressive increase in vertical cup-to-disc ratio (VCDR) found in patients with POAG. ${ }^{30}$

Compared with patients who lack glaucoma risk alleles, patients carrying the risk alleles ${ }^{31}$ (rs7049105 and rs10120688) have a lower IOP and a larger VCDR ${ }^{32}$ and are predisposed to the development of POAG at lower IOP levels, with carriers recording nearly peak IOPs of $3 \mathrm{~mm} \mathrm{Hg}$ less than non-carriers. In other words, these patients exhibit stronger associations with NTG and advanced glaucoma phenotypes. ${ }^{31}$ This finding demonstrates out that they might also be classed as severity markers for POAG. A free of adverse effects and lowering intraocular therapy is beneficial in patients at risk of disease progression. ${ }^{33}$

The possible explanations for how these risk alleles may predispose or increase the risk of glaucoma are by conferring a risk non-dependent of IOP and by increasing the susceptibility to IOP, which means increasing the sensitivity of RGCs to IOP. Importantly, these risk alleles may manage to specifically affect both the regulation of IOP and the physiology of the RGC. Cell cycle regulation is known to be possibly affected by altered gene expression, leading the RGCs to a tendency towards apoptosis. Cells in carriers may then become more sensitive to IOP, such that pressures still contribute to optic nerve damage even when statistically normal. ${ }^{23}$

Individuals exhibiting an elevated IOP without the presence of optic nerve damage may only carry genetic variants that can influence IOP regulation, while those with NTG may primarily carry genetic variants predisposed to RGG death, as the nerve degeneration in this case does not have the added stress of elevated IOP. ${ }^{33}$

\section{Regulation of CDKN2A and CDKN2B}

Two proteins are encoded by CDKN2A: p16INK4A and $\mathrm{p} 14^{\mathrm{ARF}}$, which regulate the cell cycle and act as tumour suppressors. CDKN2A products regulate the $\mathrm{Rb}$ (retinoblastoma protein) and p53 (phosphoprotein p53) pathways, which reportedly involved in RGC apoptosis and the induction of cell cycle arrest, apoptosis and senescence. ${ }^{34} C D K N 2 B$ encodes p15INK4B, a protein believed to play an important role in cell growth regulation through inducing G1 phase cell cycle arrest and is likely induced by transforming growth factor beta (TGF- $\beta$ ). ${ }^{35}$ TGF- $\beta$ modulates developmental and repair processes in several tissues, as well as participates to a considerable degree in programmed cell death in the developing retina and optic nerve. ${ }^{36} 37$

Patients with glucoma tend to have a higher aqueous humour concentration of TGF- $\beta 2$ (the predominant isoform of TGF- $\beta$ in ocular tissue) than normal individuals, 
suggesting a link between a high level of TGF- $\beta 2$ and the pathogenesis of the disease. ${ }^{38}$ CDKN2B-AS1 apparently participates in the transcription regulation of CDKN2A/ CDKN2B, and it has been noted that ANRIL depletion (deletion of the $3=$ end) in transgenic mice leads to excessive proliferation and diminished senescence in aortic smooth muscle cells, suggesting a key role in cell cycle regulation. Comparatively, the reduced cardiac expression of CDKN2A and CDKN2B in these mice was also pointed out and may be the mechanism through which CDKN2B-AS1 can alter cell cycle regulation. ${ }^{40} 4$

To further decipher the nature of their interaction and involvement in the pathogenesis of glaucoma, researchers performed a PCR analysis of their expressions in a rat model of glaucoma. One week after ocular hypertension induction, an upregulation in the expression in CDKN2A and CDKN2B was observed in the retina, which corresponds to a time point of ongoing RGC death, as indicated by the presence of axonal cytoskeleton damage in the optic nerve of the animals studied. ${ }^{24} \mathrm{CDKN} 2 \mathrm{~A}$ and CDKN2B seem to be involved in inducing apoptosis in response to stress in terminally differentiated neurons, which are of particular relevance to glaucoma, a disease characterised pathologically by the apoptosis of RGCs and loss of their axons. ${ }^{42}$

According to previous research on animal studies, elevated IOP is implicated in the overexpression of CDKN2B, which is responsible for abnormal cell proliferation because it disrupts the normal cell cycle. ${ }^{43} \mathrm{CDKN} 2 \mathrm{~A}$, previously found to be down regulated in neurodegenerative disorders such as Alzheimer disease, can equally be regulated by CDKN2B-AS1, which suggest that regulation of CDKN2A by CDKN2B-AS1 could also contribute to degeneration of the optic nerve in glaucoma. ${ }^{25} 44$

\section{MALAT1}

Metastasis-associated lung adenocarcinoma transcript 1 (MALAT1), also known as non-coding nuclear-enriched abundant transcript 2 (NEAT2), is a long non-coding RNA highly expressed in the nucleus and located on chromosome $11^{45}$. It acts as a critical regulator of neurodegeneration and has been successfully identified in diverse physiological processes, and a variety of evidence indicates its implication in various pathological processes, including diabetes-induced retinal microvascular dysfunction. ${ }^{46}$

MALAT1 participates in the regulation of the gene expression involved in nuclear and synapse function and synaptogenesis in neurons and has been demonstrated by previous studies to play a positive role in apoptosis, tumour cell proliferation, migration, invasion or the metastatic spread of tumour cells. ${ }^{47}{ }^{48}$ Recent studies conducted to determine and define its role in retinal neurodegeneration not only discovered a significant upregulation of MALAT1 in the cerebellum, hippocampus and brain stem of human alcoholics ${ }^{49}$ and many solid tumours ${ }^{50}$ but also revealed its possible involvement in diabetes-induced retinal microvascular dysfunction. ${ }^{46}$
MALAT1 can promote cell proliferation by activating the PI3K/Akt pathway, ${ }^{51}{ }^{52}$ and MALAT1 downregulation can lead to decreased visual function and retinal cell apoptosis. ${ }^{53}$ Further investigations on whether MALAT1 dysregulation can be equally observed in other neurological diseases such as glaucoma have been conducted by performing qRT-PCRs to compare MALAT1 levels in aqueous humour samples from glaucoma and cataracts patients without ocular neurodegenerative diseases. The results showed comparatively downregulated MALAT1 levels in the aqueous humour of patients with glaucoma. $^{54}$

Additional clinical and animal experiments discovered that MALAT1 knockdown may potentially affect the regenerative ability of Müller cells and contribute to the reduced expression of neurotrophic factor, thus decreasing the protection of the retina. ${ }^{54}$ The knockout of MALAT1 results in delayed vessel extension, reduced density at the vascular front and decreased proliferating cells. Microarray and quantitative PCR analyses further suggest that the promigratory and antiproliferative effects of silencing MALAT1 may be due to its downregulation of the S-phase cell cycle cyclins and upregulation of cell cycle inhibitory genes. These results implicate that during normal development, the high expression of lncRNA-MALAT1 in endothelial cells may help maintain proliferative state of these cells. ${ }^{55}$ Müller cells are the major glial component of the retina and participate in retinal homeostasis and intervene in the regulation of retinal blood flow. ${ }^{56}$ They are said to be reactivated (gliosis) in the retinas of patients with POAG, and their activation actually consists of releasing neurotrophic factors favouring the protection of the retina from a wide variety of pathological stimuli, including ischaemia, trauma and degeneration. ${ }^{57-59}$ Nonetheless, The disturbance of retinal metabolism or a primary Müller cell insufficiency, such as in certain forms of glaucoma, may participate in the production and release of cytotoxic factors, increase the susceptibility of neurons to stressful stimuli, and cause and/ or aggravate neuronal cell death after undergoing a variety of changes in morphological, physiology and biochemistry features. ${ }^{6061}$

Nakazawa et al created an ischaemic model of optic nerve injury with optic nerve crush and found that PI3K/ Akt pathway activation is actually responsible for the production of a neuroprotective effect against retinal and optic nerve injury. ${ }^{53}$

Recent investigations on this protective effect and mechanism of MALAT1 in glaucomatous RGCs ${ }^{62}$ did provide strong evidence that MALAT1 could also be implicated in the inhibition process of RGC apoptosis through the activation of the PI3K/Akt signalling pathway. Since this inhibition process protects RGCs, inhibits the occurrence of apoptosis and promotes axonal regeneration in both glaucoma and optic neuropathy, ${ }^{63} 64$ it provides a new approach for the clinical treatment of these conditions. ${ }^{62}$ 
LOXL1-AS1

Exfoliation syndrome (XFS) or pseudoexfoliation syndrome (PXF) is an age-related blinding disorder characterised by the production and accumulation of abnormal extracellular material in both ocular and non-ocular tissues. ${ }^{65}$ XFS is the most common identifiable cause of open-angle glaucoma and affects 60-70 million people worldwide. ${ }^{66}$ Patients with XFS are allegedly at a greater risk of developing a specific form of glaucoma called exfoliation glaucoma (XFG), with roughly half of the eyes with XFS developing the disease within 15 years of diagnosis. ${ }^{67} \mathrm{XFG}$ which accounts for approximately $25 \%$ of all glaucomas possesses comparatively advanced visual field defects, a higher IOP as well as a reduced response to medical treatment as main characteristics compared with POAG. ${ }^{68}$

During pupillary movement, exfoliation material is scraped from the lens surface by the iris, causing a rupture of iris pigment epithelial cells and leading to pigment dispersion into the anterior chamber and its deposition on anterior chamber structures.

The white deposit appearance of the material in the eye can be perceived on the anterior lens surface and/or pupillary border. ${ }^{69}$ Behavioural factors, such as caffeine intake, latitude of residence and vitamin deficiency, have been demonstrated to influence the risk of developing $\mathrm{XFS}$ and $\mathrm{XFG} .{ }^{70-72}$

The LOXL1 gene, a member of the lysyl oxidase family, participates in the formation and maintenance of elastic tissue and, by inducing cross-linking in collagen and elastin molecules, plays a significant role in maintaining the equilibrium of the extracellular matrix $(\mathrm{ECM}){ }^{73} \mathrm{It}$ is expressed in ocular tissues, such as the cornea, ciliary muscle, lens epithelium, lamina cribrosa and trabecular meshwork, all of which are supposedly involved in the formation of the ECM. An alteration in its activation, processing and or substrate specificity can affect the function and synthesis of extracellular tissues. ${ }^{7475}$

LOXL1 polymorphisms have previously been suggested by a large number of studies to be associated with XFS in different populations, including Caucasians (Europe, Australia and North America), Asians (China and Japan) and South Africans.

Unfortunately, these studies primarily produced inconclusive results because alleles that reportedly increase the risk of developing XFS and XFG among Caucasians (rs1048661 and rs3825942) were also shown to have a protective effect in Japanese populations. ${ }^{76-78}$ Further investigations into LOXL1 and its involvement in XFS pathogenesis discovered that the strongest evidence for an association with an increased XFS risk was located within the first intron of LOXL1, which contains variants that possibly alter the promoter for LOXL1-AS1. ${ }^{79}$

LOXL1-AS1 (LOXL1 antisense RNA 1) is a long non-coding RNA that is encoded by the opposite strand of LOXL1. It is broadly expressed in tissues known to be affected in XFS, and its expression can be altered by XFS-relevant cell stressors, such as oxidative stress in lens epithelial cells and cyclic mechanical stress in Schlemm's canal, suggesting a critical role in the cell stress response. ${ }^{79}$ The expression of many genes involved in various processes and XFG pathophysiology, such as collagen fibril formation (COL6A3, LOXL4), ECM degradation (TIMP3), cytoskeleton integrity (ACTA2), calcium ion binding (EFHD2), and response to oxidative stress (HMOX1), are actually modulated by the LOXL1-AS1.

LOXL1-AS1 knockdown has been demonstrated to alter the expression of up to 109 genes, including those related to ECM constituents. The dysregulated expression of LOXL1-AS1 may contribute to XFS and XFG pathogenesis because genetic risk variants and environmental stressors altering the level of LOXL1-AS1 disrupt the equilibrium of the ECM by affecting the gene expression of other XFS-relevant genes, potentially contributing to the pathogenesis of these complex inherited diseases. ${ }^{81}$

Additionally, it has been proven that the altered expression of LOXL1-AS1 levels has functional relevance in other organs and tissues affected in XFS including stem cells. This implies the possible implication of LOXL1-AS1 in increasing the risk of cerebrovascular diseases in patients with XFS. Similarly, increased oxidative stress is observed in neurodegenerative disorders, which are also associated with XFS, suggesting that LOXL1-AS1 dysregulation and abnormal response to oxidative stress play a role in these disease states. ${ }^{82}$

\section{ASMM10P055228 and ASMM10P040128}

Optineurin, also called optic neuropathy-inducing protein, is a protein that is encoded by the OPTN gene and the second identified glaucoma causative gene through investigations of large NTG pedigrees. ${ }^{83}$ The OPTN gene is located on chromosome 10p15-14, ubiquitously expressed in both non-ocular and ocular tissues ${ }^{84}$ that include the trabecular meshwork, non-pigmented ciliary epithelium, retina, brain, heart, skeletal muscle, placenta and kidney; and mutations in this gene have been linked to POAG and NTG. ${ }^{85}$

OPTN mutations in transgenic mice models, including E50, have been identified as a key element in RGC apoptosis in previous studies; however, specific mechanisms remain largely unknown. ${ }^{86}$ Recent studies have aimed to investigate the expression of differentially expressed lncRNAs in OPTN (E50K) transgenic and wild-type mice. For this purpose, six retinas from 8-month-old transgenic and wild-type mice were collected, divided into different groups and analysed independently for levels of lncRNA expression, which were later compared between mutant and wild groups by performing a two-tailed t-test.

The results revealed various differentially expressed lncRNAs between the OPTN (E50K) transgenic and wild-type mice; in addition, the pathway analysis contributed to the annotation of ASMM10P055228 and ASMM10P040128, two lncRNAs suspected to be responsible for the negative regulation of oxidative stress-induced cell death and regulation of the execution 
phase of apoptosis, which may be the underlying mechanism for POAG.

Although observations about the discovery of differentially expressed lncRNAs in the retinas between OPTN (E50K) transgenic and wild-type mice remain preliminary;and require further investigations to help clarify pathogenetic pathways, this finding is still attracting increasing interest as it creates a paradigm regarding the function of lncRNAs for detecting POAG pathogenesis. ${ }^{87}$

\section{CONCLUSION}

Glaucoma is a complex disease because genetic and environmental factors both play important roles in its pathogenesis, therefore and despite the tremendous progress achieved in the last decade, the genetic basis of glaucoma is still not completely understood. Although IncRNAs have previously been linked with diverse diseases, however the proper connections and pathways they may use to influence the susceptibility to developing glaucoma have not yet been completely elucidated.

By summarising results from separate independent glaucoma-related studies, we reviewed lncRNAs characteristics and regulation, and tried to discuss potential pathways by which CDKN2B-AS1, MALAT1, LOXL1-AS1, ASMM10P055228 and ASMM10P040128 may contribute to glaucoma.

However, further researches and investigations are needed to discover vast number of glaucoma-associated lncRNAs, their characteristics and expression patterns, and decipher pathways of their involvement and role in the pathogenesis of this blinding disease. Since most glaucomas are symptomless at early stages, we stress that this article creates a paradigm for future studies of lncRNAs in the prevention, early determination and monitoring of the evolution of glaucoma and may prove to be useful to define high-risk or low-risk alleles for early determination of whether a patient with a suspected glaucoma allele should receive prioritised treatment to help slow the progression of the disease, reduce further damage to the optic nerve and subsequently avoid blindness, and retain quality of life.

Acknowledgements The authors are thankful to all members of Bai Lang's research group for their participation and critical assessments of this manuscript.

Contributors CY: conception, design, literature search and writing of the manuscript. BL: supervision. BL and MT: critical reading. All authors: approval of the final proofs of the article.

Funding This research is supported by the National Natural Science Foundation of China (Grant No. 81170887), the Natural Science Foundation of Guangdong Province (Grant No. 2017A030313602) and the Horizontal Topic Matching Funds of Nanfang Hospital, Southern Medical University (Grant No. G201202).

Competing interests None declared.

Patient consent Detail has been removed from this case description/these case descriptions to ensure anonymity. The editors and reviewers have seen the detailed information available and are satisfied that the information backs up the case the authors are making.

Provenance and peer review Not commissioned; internally peer reviewed.

Open Access This is an Open Access article distributed in accordance with the Creative Commons Attribution Non Commercial (CC BY-NC 4.0) license, which permits others to distribute, remix, adapt, build upon this work non-commercially, and license their derivative works on different terms, provided the original work is properly cited and the use is non-commercial. See: http://creativecommons.org/ licenses/by-nc/4.0/

(c) Article author(s) (or their employer(s) unless otherwise stated in the text of the article) 2018. All rights reserved. No commercial use is permitted unless otherwise expressly granted.

\section{REFERENCES}

1. Mantravadi AV, Vadhar N. Glaucoma. Prim Care 2015;42:437-49.

2. Friedman DS, Wolfs RC, O'Colmain BJ, et al. Prevalence of openangle glaucoma among adults in the United States. Arch Ophthalmol 2004;122:532-8.

3. Quigley HA, Broman AT. The number of people with glaucoma worldwide in 2010 and 2020. Br J Ophthalmol 2006;90:262-7.

4. Tham YC, Li X, Wong TY, et al. Global prevalence of glaucoma and projections of glaucoma burden through 2040: a systematic review and meta-analysis. Ophthalmology 2014;121:2081-90.

5. Global data on blindness.pdf

6. Klein BE, Klein R, Lee KE. Heritability of risk factors for primary open-angle glaucoma: the Beaver Dam Eye Study. Invest Ophthalmol Vis Sci 2004;45:59-62.

7. Kong $\mathrm{X}$, Chen $\mathrm{Y}$, Chen $\mathrm{X}$, et al. Influence of family history as a risk factor on primary angle closure and primary open angle glaucoma in a Chinese population. Ophthalmic Epidemiol 2011;18:226-32.

8. Stone EM, Fingert JH, Alward WL, et al. Identification of a gene that causes primary open angle glaucoma. Science 1997;275:668-70.

9. Rezaie T, Child A, Hitchings R, et al. Adult-onset primary openangle glaucoma caused by mutations in optineurin. Science 2002;295:1077-1079.

10. Chen $Y$, Chen $X$, Wang L, et al. Extended association study of PLEKHA7 and COL11A1 with primary angle closure glaucoma in a Han Chinese population. Invest Ophthalmol Vis Sci 2014;55:3797-802.

11. Esteller M. Non-coding RNAs in human disease. Nat Rev Genet 2011;12:861-74.

12. Ramos AD, Andersen RE, Liu SJ, et al. The long noncoding RNA Pnky regulates neuronal differentiation of embryonic and postnatal neural stem cells. Cell Stem Cell 2015;16:439-47.

13. Faghihi MA, Modarresi $F$, Khalil AM, et al. Expression of a noncoding RNA is elevated in Alzheimer's disease and drives rapid feed-forward regulation of beta-secretase. Nat Med 2008;14:723-30.

14. Greene LA, Liu DX, Troy CM, et al. Cell cycle molecules define a pathway required for neuron death in development and disease. Biochim Biophys Acta 2007;1772:392-401.

15. Helgadottir A, Thorleifsson G, Manolescu A, et al. A common variant on chromosome 9p21 affects the risk of myocardial infarction. Science 2007:316:1491-3.

16. Scott LJ, Mohlke KL, Bonnycastle LL, et al. A genome-wide association study of type 2 diabetes in Finns detects multiple susceptibility variants. Science 2007;316:1341-5.

17. Matarin M, Brown WM, Singleton A, et al. Whole genome analyses suggest ischemic stroke and heart disease share an association with polymorphisms on chromosome 9p21. Stroke 2008;39:1586-9.

18. Helgadottir A, Thorleifsson G, Magnusson KP, et al. The same sequence variant on 9p21 associates with myocardial infarction, abdominal aortic aneurysm and intracranial aneurysm. Nat Genet 2008;40:217-24.

19. Shete S, Hosking FJ, Robertson LB, et al. Genome-wide association study identifies five susceptibility loci for glioma. Nat Genet 2009;41:899-904.

20. Bishop DT, Demenais F, lles MM, et al. Genome-wide association study identifies three loci associated with melanoma risk. Nat Genet 2009;41:920-5

21. Pasmant $E$, Sabbagh $A$, Vidaud $M$, et al. ANRIL, a long, noncoding RNA, is an unexpected major hotspot in GWAS. Faseb $J$ $2011 ; 25: 444-8$

22. Ng SK, Casson RJ, Burdon KP, et al. Chromosome 9p21 primary open-angle glaucoma susceptibility locus: a review. Clin Exp Ophthalmol 2014;42:25-32

23. Wiggs JL, Yaspan BL, Hauser MA, et al. Common variants at 9p21 and 8 q22 are associated with increased susceptibility to optic nerve degeneration in glaucoma. PLoS Genet 2012;8:e1002654.

24. Burdon KP, Macgregor S, Hewitt AW, et al. Genome-wide association study identifies susceptibility loci for open angle glaucoma at TMCO1 and CDKN2B-AS1. Nat Genet 2011;43:574-8. 
25. Congrains A, Kamide K, Ohishi M, et al. ANRIL: molecular mechanisms and implications in human health. Int $\mathrm{J} \mathrm{Mol} \mathrm{Sci}$ 2013;14:1278-92.

26. Pasquale LR, Loomis SJ, Kang JH, et al. CDKN2B-AS1 genotypeglaucoma feature correlations in primary open-angle glaucoma patients from the United States. Am J Ophthalmol 2013;155:342-53.

27. Nakano M, Ikeda Y, Tokuda Y, et al. Common variants in CDKN2BAS1 associated with optic-nerve vulnerability of glaucoma identified by genome-wide association studies in Japanese. PLoS One 2012;7:e33389.

28. Osman W, Low SK, Takahashi A, et al. A genome-wide association study in the Japanese population confirms 9p21 and 14q23 as susceptibility loci for primary open angle glaucoma. Hum Mol Genet 2012;21:2836-42

29. Li Z, Allingham RR, Nakano M, et al. A common variant near TGFBR3 is associated with primary open angle glaucoma. Hum Mol Genet 2015;24:3880-92.

30. Bellezza AJ, Hart RT, Burgoyne CF. The optic nerve head as a biomechanical structure: initial finite element modeling. Invest Ophthalmol Vis Sci 2000;41:2991-3000.

31. Burdon KP, Crawford A, Casson RJ, et al. Glaucoma risk alleles at CDKN2B-AS1 are associated with lower intraocular pressure, normal-tension glaucoma, and advanced glaucoma. Ophthalmology 2012;119:1539-45.

32. Ramdas WD, van Koolwijk LM, Ikram MK, et al. A genomewide association study of optic disc parameters. PLoS Gene 2010;6:e1000978.

33. Group CN-TGS. Comparison of glaucomatous progression between untreated patients with normal-tension glaucoma and patients with therapeutically reduced intraocular pressures. Collaborative Normal-Tension Glaucoma Study Group. Am J Ophthalmol 1998;126:487-97.

34. Gil J, Peters G. Regulation of the INK4b-ARF-INK4a tumour suppressor locus: all for one or one for all. Nat Rev Mol Cell Biol 2006;7:667-77.

35. Hannon GJ, Beach D. p15INK4B is a potential effector of TGF-betainduced cell cycle arrest. Nature 1994;371:257-61.

36. Pena JD, Taylor AW, Ricard CS, et al. Transforming growth factor beta isoforms in human optic nerve heads. Br J Ophthalmol 1999;83:209-18

37. Duenker N. Transforming growth factor-beta (TGF-beta) and programmed cell death in the vertebrate retina. Int Rev Cytol 2005;245:17-43.

38. Ozcan AA, Ozdemir N, Canataroglu A. The aqueous levels of TGFbeta2 in patients with glaucoma. Int Ophthalmol 2004;25:19-22.

39. Trivedi $\mathrm{RH}$, Nutaitis $\mathrm{M}$, Vroman D, et al. Influence of race and age on aqueous humor levels of transforming growth factor-beta 2 in glaucomatous and nonglaucomatous eyes. J Ocul Pharmacol Ther 2011:27:477-80

40. Visel A, Zhu Y, May D, et al. Targeted deletion of the 9p21 noncoding coronary artery disease risk interval in mice. Nature 2010;464:409-12.

41. Fuchshofer $R$. The pathogenic role of transforming growth factor- $\beta 2$ in glaucomatous damage to the optic nerve head. Exp Eye Res 2011;93:165-9.

42. Currais A, Hortobágyi T, Soriano S. The neuronal cell cycle as a mechanism of pathogenesis in Alzheimer's disease. Aging 2009;1:363-71.

43. Iglesias Al, Springelkamp $\mathrm{H}$, van der Linde $\mathrm{H}$, et al. Exome sequencing and functional analyses suggest that SIX6 is a gene involved in an altered proliferation-differentiation balance early in life and optic nerve degeneration at old age. Hum Mol Genet 2014;23:1320-32

44. Pogue Al, Cui JG, Li YY, et al. Micro RNA-125b (miRNA-125b) function in astrogliosis and glial cell proliferation. Neurosci Lett 2010;476:18-22.

45. Hutchinson JN, Ensminger AW, Clemson CM, et al. A screen for nuclear transcripts identifies two linked noncoding RNAs associated with SC35 splicing domains. BMC Genomics 2007;8:39.

46. Liu JY, Yao J, Li XM, et al. Pathogenic role of IncRNA-MALAT1 in endothelial cell dysfunction in diabetes mellitus. Cell Death Dis 2014;5:e1506.

47. Qiu MT, Hu JW, Yin R, et al. Long noncoding RNA: an emerging paradigm of cancer research. Tumour Biol 2013;34:613-20.

48. Bernard D, Prasanth KV, Tripathi V, et al. A long nuclear-retained non-coding RNA regulates synaptogenesis by modulating gene expression. Embo J 2010;29:3082-93.

49. Kryger R, Fan L, Wilce PA, et al. MALAT-1, a non protein-coding RNA is upregulated in the cerebellum, hippocampus and brain stem of human alcoholics. Alcohol 2012;46:629-34.
50. Gutschner T, Hämmerle M, Diederichs S. MALAT1 - a paradigm for long noncoding RNA function in cancer. $J$ Mol Med 2013;91:791-801.

51. Zhao J, Li L, Peng L. MAPK1 up-regulates the expression of MALAT1 to promote the proliferation of cardiomyocytes through PI3K/AKT signaling pathway. Int J Clin Exp Pathol 2015:8:15947-53.

52. Dong Y, Liang G, Yuan B, et al. MALAT1 promotes the proliferation and metastasis of osteosarcoma cells by activating the PI3K/Akt pathway. Tumour Biol 2015;36:1477-86.

53. Nakazawa T, Shimura M, Tomita $\mathrm{H}$, et al. Intrinsic activation of PI3K/ Akt signaling pathway and its neuroprotective effect against retinal injury. Curr Eye Res 2003;26:55-63.

54. Yao J, Wang XQ, Li YJ, et al. Long non-coding RNA MALAT1 regulates retinal neurodegeneration through CREB signaling. EMBO Mol Med 2016;8:346-62.

55. Michalik KM, You X, Manavski Y, et al. Long noncoding RNA MALAT1 regulates endothelial cell function and vessel growth. Circ Res 2014;114:1389-97.

56. Bringmann A, Pannicke T, Grosche J, et al. Müller cells in the healthy and diseased retina. Prog Retin Eye Res 2006;25:397-424.

57. Barres BA. The mystery and magic of glia: a perspective on their roles in health and disease. Neuron 2008:60:430-40.

58. Mamczur P, Borsuk B, Paszko J, et al. Astrocyte-neuron crosstalk regulates the expression and subcellular localization of carbohydrate metabolism enzymes. Glia 2015;63:328-40.

59. Ruzafa N, Vecino E. Effect of Müller cells on the survival and neuritogenesis in retinal ganglion cells. Arch Soc Esp Oftalmol 2015;90:522-6.

60. Gao F, Ji M, Wu JH, et al. [Roles of retinal Müller cells in health and glaucoma]. Sheng Li Xue Bao 2013;65:654--63.

61. Seitz R, Ohlmann A, Tamm ER. The role of Müller glia and microglia in glaucoma. Cell Tissue Res 2013;353:339-45.

62. Li HB, You QS, Xu LX, et al. Long Non-Coding RNA-MALAT1 Mediates Retinal Ganglion Cell Apoptosis Through the PI3K/Akt Signaling Pathway in Rats with Glaucoma. Cell Physiol Biochem 2017;43:2117-32.

63. Luo JM, Cen LP, Zhang XM, et al. PI3K/akt, JAK/STAT and MEK/ERK pathway inhibition protects retinal ganglion cells via different mechanisms after optic nerve injury. Eur $\mathrm{J}$ Neurosci 2007:26:828-42.

64. Li SY, Yau SY, Chen BY, et al. Enhanced survival of melanopsinexpressing retinal ganglion cells after injury is associated with the PI3 K/Akt pathway. Cell Mol Neurobiol 2008;28:1095-107.

65. Miglior S, Bertuzzi F. Exfoliative glaucoma: new evidence in the pathogenesis and treatment. Prog Brain Res 2015;221:233-41.

66. Ritch R. Exfoliation syndrome-the most common identifiable cause of open-angle glaucoma. J Glaucoma 1994;3:176-7.

67. Jeng SM, Karger RA, Hodge DO, et al. The risk of glaucoma in pseudoexfoliation syndrome. J Glaucoma 2007;16:117-21.

68. Vesti E, Kivelä T. Exfoliation syndrome and exfoliation glaucoma. Prog Retin Eye Res 2000;19:345-68.

69. Ritch R. Ocular and systemic manifestations of exfoliation syndrome. $J$ Glaucoma 2014:23:S1-S8

70. Stein JD, Pasquale LR, Talwar N, et al. Geographic and climatic factors associated with exfoliation syndrome. Arch Ophthalmol 2011;129:1053-60.

71. Pasquale LR, Wiggs JL, Willett WC, et al. The Relationship between caffeine and coffee consumption and exfoliation glaucoma or glaucoma suspect: a prospective study in two cohorts. Invest Ophthalmol Vis Sci 2012;53:6427-33.

72. Kang JH, Loomis SJ, Wiggs $\mathrm{JL}$, et al. A prospective study of folate, vitamin $\mathrm{B} \square$, and vitamin $\mathrm{B} \square \square$ intake in relation to exfoliation glaucoma or suspected exfoliation glaucoma. JAMA Ophthalmol 2014:132:549-59.

73. Csiszar K. Lysyl oxidases: a novel multifunctional amine oxidase family. Prog Nucleic Acid Res Mol Biol 2001;70:1-32.

74. Pena JD, Netland PA, Vidal I, et al. Elastosis of the lamina cribrosa in glaucomatous optic neuropathy. Exp Eye Res 1998;67:517-24.

75. Kirwan RP, Fenerty $\mathrm{CH}$, Crean J, et al. Influence of cyclical mechanical strain on extracellular matrix gene expression in human lamina cribrosa cells in vitro. Mol Vis 2005;11:798-810.

76. Álvarez L, García M, González-Iglesias H, et al. LOXL1 gene variants and their association with pseudoexfoliation glaucoma (XFG) in Spanish patients. BMC Med Genet 2015;16:72.

77. Jonasson F. From epidemiology to lysyl oxidase like one (LOXL1) polymorphisms discovery: phenotyping and genotyping exfoliation syndrome and exfoliation glaucoma in Iceland. Acta Ophthalmol 2009;87:478-87.

78. Ramprasad VL, George R, Soumittra N, et al. Association of non-synonymous single nucleotide polymorphisms in the 
LOXL1 gene with pseudoexfoliation syndrome in India. Mol Vis 2008;14:318--22.

79. Hauser MA, Aboobakar IF, Liu Y, et al. Genetic variants and cellular stressors associated with exfoliation syndrome modulate promoter activity of a IncRNA within the LOXL1 locus. Hum Mol Genet 2015;24:6552-63.

80. Aboobakar IF, Johnson WM, Stamer WD, et al. Major review: exfoliation syndrome; advances in disease genetics, molecular biology, and epidemiology. Exp Eye Res 2017;154:88-103.

81. Aboobakar IF, Qin X, Stamer WD, et al. A IncRNA in the LOXL1 locus modulates expression of genes relevant to exfoliation glaucoma pathobiology. Invest Ophthalmol Vis Sci 2016;57:790-90.

82. Ramalingam M, Kim SJ. Reactive oxygen/nitrogen species and their functional correlations in neurodegenerative diseases. J Neural Transm 2012;119:891-910.
83. Rezaie T, Child A, Hitchings R, et al. Adult-onset primary openangle glaucoma caused by mutations in optineurin. Science 2002;295:1077-9.

84. Sarfarazi M, Rezaie T. Optineurin in primary open angle glaucoma. Ophthalmol Clin North Am 2003;16:529-41.

85. Fuse N, Takahashi K, Akiyama H, et al. Molecular genetic analysis of optineurin gene for primary open-angle and normal tension glaucoma in the Japanese population. J Glaucoma 2004;13:299-303.

86. Chi ZL, Akahori M, Obazawa M, et al. Overexpression of optineurin E50K disrupts Rab8 interaction and leads to a progressive retinal degeneration in mice. Hum Mol Genet 2010;19:2606-15.

87. Li Y, Jin L, Dong A, et al. Microarray expression profile analysis of long non-coding RNAs in optineurin E50K mutant transgenic mice. Mol Med Rep 2017;16:1255-61. 